\title{
A REDE SOCIAL E O ACOLHIMENTO INSTITUCIONAL DE CRIANÇAS E ADOLESCENTES: A (RE) CONSTRUÇÃO DOS DIREITOS AMEAÇADOS OU VIOLADOS
}

\author{
SOCIAL NETWORKING AND THE CHILDREN AND ADOLESCENT \\ INSTITUTIONAL SHELTERING: (RE)CONSTRUCTION OF THE THREATENED \\ OR VIOLATED RIGHTS
}

Cláudia Helena Julião ${ }^{1}$

Fernanda Aguiar Pizeta ${ }^{2}$

\begin{abstract}
RESUMO: A temática da ameaça ou violação de direitos de crianças e adolescentes se revestiu de importância na realidade brasileira diante à instituição do Estatuto da Criança e do Adolescente. Dentre as medidas de proteção à infância e juventude, destaca-se o acolhimento institucional, que, por sua natureza, deve ser aplicado excepcionalmente e em situações nas quais a permanência da criança ou adolescente na família em que se encontra é condição de risco ao seu desenvolvimento bio-psico-social. Nas últimas décadas, as diversas esferas governamentais e da sociedade civil organizada vêm priorizando a construção de um modelo de acolhimento que se contraponha aos antigos orfanatos e internatos e que garanta $O$ direito da criança e do adolescente à convivência familiar e comunitária. A experiência como profissionais do Setor Técnico (Assistente Social e Psicólogo) do Poder Judiciário na Comarca de Batatais-SP, o contato com as instituições de acolhimento bem como com as crianças e adolescentes acolhidos e suas famílias, durante cerca de quatro anos, nos despertou o interesse pelo tema e a necessidade de maior conhecimento e reflexão sobre o mesmo. Dessa forma, o presente trabalho se constitui no resultado de pesquisa bibliográfica realizada sobre tão polêmica problemática e da experiência vivenciada pelas autoras no município de Batatais na construção da rede social voltada para oferecer suporte às famílias cujos filhos foram acolhidos institucionalmente. Evidenciou-se imprescindível para a avaliação, encaminhamento e acompanhamento às famílias atendidas pelo Judiciário, com história ou demanda de acolhimento institucional, a identificação e a articulação eficaz da rede de apoio social e comunitária disponível para estas famílias, de forma que estas possam assumir os cuidados com seus membros, mediante a potencialização de seus recursos internos bem como a efetividade dos recursos externos.
\end{abstract}

Palavras-chave: Família. Acolhimento Institucional. Criança. Adolescente. Rede Social.

\footnotetext{
${ }^{1}$ Profa. Adjunto da UFTM- Curso de Serviço Social. End: Avenida Getúlio Guaritá, 159 AbadiaUberaba-MG claudiahj@servicosocial.uftm.edu.br - tel: (34) 3318-5947.

${ }^{2}$ Psicóloga Judiciária- Comarca de Batatais-SP. End: Praça Doutor José Arantes Junqueira, s/n. Batatais-SP fpizeta@tjsp.jus.br - tel: (16) 3761-2499
} 
ABSTRACT: The theme of threat or violation of children and adolescents rights has been considered important in the Brazilian reality before de institution of the Child and Adolescent Statute. Among the measures to protect children and youth, there is the institutional sheltering, which by its nature, must be applied in exceptional circumstances and situations in which the permanence of the child or adolescent in the family where they are in a condition of risk to their bio-psycho-social development. In recent decades, the various spheres of government and the organized civil society have prioritized the construction of a model of sheltering that goes against the old orphanages and boarding schools and that ensure the right of children and adolescents to family and community live. The experience as professionals Technical Sector (Social Worker and Psychologist) of the Judiciary in the County of Batatais-SP, and the contact with host institutions as well as with children and adolescents sheltered and their families, for about four years, woke us up interest in the topic and aroused our need for greater knowledge and reflection on it. Thus, the present work is the result of research literature on such controversial issues and of the experience lived by the authors in the municipality of Batatais in building the social network dedicated to support families whose children were sheltered institutionally. It was proven indispensable to the evaluation, referral and follow-up to families assisted by the Judiciary, with a history or demand for institutional sheltering, the identification and effective coordination of the social and community support network available to these families so that they can take care for its members by leveraging their internal resources and the effectiveness of external resources.

Keywords: family. Institutional Sheltering. Child. Adolescent. Social Networking 


\section{INFÂNCIA E JUVENTUDE: ASPECTOS LEGAIS E HISTÓRICOS}

O olhar sobre a infância e a juventude no Brasil nos revela que o tratamento dispensado às crianças e adolescentes passou por diversas modificações no decorrer da história. Tivemos desde ações repressivas e discriminatórias, até o enfoque de proteção integral, preconizado pelo Estatuto da Criança e do Adolescente e por suas reformulações mais atuais.

Foi um longo caminho no qual tivemos a transição de ações assistencialistas e filantrópicas voltadas para crianças e adolescentes, considerados inicialmente como "menores", "abandonados", "carentes", até a efetiva consolidação de uma política social voltada à infância e juventude. Destacaremos, a seguir, alguns aspectos da trajetória da legislação e das políticas de atendimento à criança e ao adolescente em nosso país, relevantes para a compreensão dessa transição e do lugar que este segmento ocupa na sociedade. Assim, se faz importante, além de conhecer tal legislação, analisar as suas consequências para a sociedade e, de modo especial, para as crianças e adolescentes.

Nas primeiras décadas da colonização brasileira, destacam-se ações incipientes de "proteção" à infância, cuja tônica estava diretamente voltada para o recolhimento de crianças. Em 1551, surge a primeira casa de recolhimento de crianças no Brasil, com a finalidade de acolher crianças índias e negras que foram separadas de seus pais como forma de isolá-las da influência dos costumes e tradições de seus antepassados e facilitar a assimilação da cultura e da religião dos portugueses.

Nessas casas de recolhimento, as crianças recebiam, além de evangelização, castigos severos, acreditando-se que o trabalho árduo poderia "garantir-lhes o céu". Assim, a igreja dá início a ações de recolhimento de crianças "desvalidas", ações estas que irão acompanhar por muito tempo sua trajetória.

Durante o período colonial, a legislação referente à infância mantém a preocupação com o recolhimento de crianças órfãs e expostas pautada na ideologia cristã. Instituições de cunho religioso e assistencial e o governo estabelecem, então, alianças com o objetivo de garantir proteção aos denominados "expostos".

Na primeira metade do século XX, a criação de instituições distintas para menores abandonados e para os delinqüentes evidencia a preocupação dos juristas e do governo da época com questões como o aumento da criminalidade infanto- 
juvenil, a regulamentação da idade penal e os dispositivos para suspensão, perda ou devolução do pátrio poder $^{3}$, resultando na regulamentação de uma legislação relativa à infância e juventude a partir da década de 1920.

Em 1927, foi aprovado o primeiro Código de Menores, que regula a situação da infância abandonada e delinquente, trazendo como conteúdo básico a questão do controle da autoridade judiciária sobre as crianças abandonadas e delinquentes. Esta lei procurou “'resolver' o problema dos menores, prevendo todos os possíveis detalhes e exercendo firme controle sobre os menores, por meio de mecanismos de 'tutela', 'guarda', 'vigilância', 'reeducação', 'reabilitação', preservação', 'reforma' e 'educação'” (RIZZINI, 2000, p. 28).

Durante o período de vigência da referida Lei (1927-1979), as políticas de atenção a crianças e adolescentes pautaram-se na concepção de tutela e coerção e, neste sentido, a internação em instituições para "menores" era uma prática corrente. A existência de uma legislação e de serviços específicos para proporcionar assistência social aos menores abandonados e infratores pode ser considerada marco importante na história social da infância e juventude no Brasil, pois significaram o reconhecimento do Estado e da sociedade do problema do "menor" como questão social.

O processo de reformulação do Código de Menores foi longo e sofreu influência dos debates que ocorreram internacionalmente, como, por exemplo, a Declaração Universal dos Direitos da Criança, aprovada pela Assembleia Geral das Nações Unidas, em 1959. Somente em 1979, o novo Código de Menores foi aprovado, ampliando os poderes do Juiz de Menores.

A partir das reformulações trazidas pelo novo Código de Menores, o sistema de atendimento ao "menor" passou a ser questionado. A nova legislação não impediu, porém, que crianças e adolescentes continuassem a ser privados de condições essenciais a sua subsistência e considerados em situação irregular. As políticas voltadas para a infância e juventude mantinham o caráter assistencialista, compensatório, centralizado e sem articulação com as demais políticas sociais.

\footnotetext{
${ }^{3}$ O Código Civil Brasileiro, em vigor desde 11 de janeiro de 2001, altera o nome pátrio poder para poder familiar, superando o uso de uma expressão que evoca o poder paterno em detrimento do materno. De acordo com o referido Código, o exercício do poder familiar compete ao pai e à mãe em igualdade de condições. O projeto de Lei $n^{\circ}$ 674, denominado Estatuto das Famílias, propõe nova alteração a essa terminologia, referindo-se à autoridade parental que reconhece a autoridade exercida pelos pais, porém estabelece limites a este exercício com destaque ao predomínio dos interesses do filho.
} 
Dessa forma, o próprio Código de Menores e as políticas de atendimento a crianças e adolescentes foram alvos de severas críticas nos anos 1980, período em que identificamos profundas transformações na sociedade brasileira e também nas instituições públicas. O processo de redemocratização que atingiu o país na referida década e a intensificação das mobilizações sociais e políticas relacionadas à questão da infância e da juventude trouxeram resultados positivos: a partir da nova Constituição (1988), o tratamento que o Estado dispensava às crianças e aos adolescentes sofreu mudanças substanciais, com a conquista de direitos e a regulamentação dos artigos 227 e 228 da Constituição através da aprovação do Estatuto da Criança e do Adolescente - ECA, em 1990.

A Constituição Federal de 1988 e o Estatuto da Criança e do Adolescente - ECA (1990) representam uma vitória no reconhecimento dos direitos básicos e fundamentais da infância e da juventude. As referidas leis marcam o início de um novo modelo de atendimento a crianças e adolescentes que passam a ser significados enquanto sujeitos de direitos, em situação peculiar de desenvolvimento. A família, o Estado e a sociedade são convocados a assumirem conjuntamente a responsabilidade pela garantia dos direitos da criança e do adolescente.

Para tanto, os recursos institucionais de atenção voltados para crianças e adolescentes em situação de abandono, bem como para suas famílias, passaram a se configurar como medidas de proteção. A principal novidade desse modelo diz respeito ao caráter provisório da medida de acolhimento institucional, bem como a preocupação com a reinserção familiar, garantindo-se assim o direito à convivência familiar, conforme previsto no parágrafo único do artigo 101 do ECA: "o abrigo é medida provisória e excepcional, utilizável como forma para a colocação em família substituta, não implicando privação de liberdade".

Instrumentos legais, como a Constituição Federal, o Plano Nacional de Promoção, Proteção e Defesa do Direito de Crianças e Adolescentes à Convivência Familiar e Comunitária e a Lei no. 12.010, aprovada em 03 de agosto de 2009, conhecida como Nova Lei de Adoção, asseguram à criança e ao adolescente o direito de serem criados e educados por sua família e, excepcionalmente, em família substituta.

Sabemos, porém, que não bastam alterações na legislação para que a sociedade também modifique sua forma de olhar e desenvolver ações em prol da 
criança e do adolescente. Prova disto é que apesar de 20 anos de existência do ECA, suas prescrições ainda não foram totalmente absorvidas pela sociedade, encontrando assim inúmeras dificuldades para sua efetiva implantação.

Trataremos, no tópico a seguir, questões relacionadas a uma das inovações da legislação vigente referente à infância e juventude, a saber: o direito à convivência familiar e comunitária.

\section{O DIREITO À CONVIVÊNCIA FAMILIAR E COMUNITÁRIA}

A família é o principal núcleo de socialização humana. Desde o nascimento, é na família que o indivíduo encontra os aportes necessários para sua sobrevivência e desenvolvimento, sendo os primeiros anos de vida da criança marcados pela dependência dos adultos, sejam eles os pais ou outras pessoas que se responsabilizem por seus cuidados. É também nesse período que a criança irá fazer aquisições importantes para o desenvolvimento de sua autonomia, socialização, coordenação motora, linguagem, afetividade, pensamento cognitivo e tantas outras habilidades fundamentais para sua formação pessoal e social.

Além da família, o contexto social é outro elemento que irá influenciar continuamente o desenvolvimento da criança e do adolescente. A relação com os pares, os professores, os vizinhos e outras famílias possibilita ao indivíduo a interação e a formação de seus próprios grupos de relacionamento. Nessa relação com a comunidade, a criança e o adolescente se deparam com o coletivo e expressam sua individualidade.

Podemos ainda ressaltar que a convivência comunitária também contribui para o "fortalecimento dos vínculos familiares e a inserção social da família", conforme aponta o Plano Nacional de Promoção, Proteção e Defesa do Direito de Crianças e Adolescentes à Convivência Familiar e Comunitária (2006, p.32).

Dessa forma, a família e a comunidade são responsáveis por preparar a criança para a vida em sociedade, mediando sua relação com o mundo e auxiliandoa a respeitar e introjetar regras, limites e normas necessárias para a vida em sociedade.

Diante desse papel essencial desempenhado pela família e pelo contexto social no crescimento e formação dos indivíduos, a convivência familiar e 
comunitária é reconhecida como um direito fundamental da criança e do adolescente.

Entretanto, é sabido que, nem sempre, a família representa um espaço de proteção para crianças e adolescentes, podendo se configurar como um contexto adverso e um lugar de violação de direitos. Essa incapacidade da família para desempenhar plenamente suas responsabilidades e funções protetivas está diretamente relacionada ao acesso a alguns serviços como saúde, educação e assistência social, que compõe parte da rede de suporte social da família.

Nesse sentido, consideramos importante a existência de estratégias de atendimento que possibilitem à família receber proteção da sociedade e do Estado, visando o resgate de sua capacidade protetiva e a preservação dos vínculos familiares. A prioridade de tais estratégias deve ser garantir à criança e ao adolescente a permanência em sua família natural, definida pelo artigo 25 do ECA como "a comunidade formada pelos pais ou qualquer deles e seus descendentes".

Contudo, destaca-se que inúmeros obstáculos podem impedir a permanência da criança e adolescente em sua família natural, depois de esgotadas todas as possibilidades de apoio à mesma. Nessas situações, nas quais as limitações das políticas públicas e/ou das próprias famílias não permitem a reinserção da criança e do adolescente em suas famílias naturais, a colocação em família substituta deve ser buscada como forma de garantir o direito à convivência familiar e comunitária, conforme preceitua o ECA:

\footnotetext{
"Toda criança ou adolescente tem direito a ser criado e educado no seio da sua família e, excepcionalmente, em família substituta, assegurada a convivência familiar e comunitária, em ambiente livre da presença de pessoas dependentes de substâncias entorpecentes" (artigo 19 do ECA).
}

A efetivação da proteção às famílias para que estas possam assegurar aos seus filhos o direito à convivência familiar exige a articulação e a integração de diferentes políticas públicas. Além disso, se faz necessário o fortalecimento do Sistema de Garantia de Direitos para que a família, a comunidade e o Estado assegurem, de fato, os direitos à criança e ao adolescente previstos na Constituição e no ECA, entre eles a convivência familiar e comunitária.

No Brasil, temos instrumentos legais, como a Constituição, o ECA e a Lei Orgânica da Assistência Social (LOAS) que reconhecem a família como merecedora 
de proteção. A existência de um projeto de lei (Projeto ํo 674 - Estatuto das Famílias) indica a relevância que se tem dado ao tema, sendo a família instituída como um direito fundamental, ampliando os perfis de entidades familiares que devem ser protegidas pelo Estado.

Ao nos referirmos à proteção especial do Estado, não podemos deixar de ressaltar as funções das políticas sociais. Essas, assim como as famílias, "visam dar conta da reprodução e da proteção social dos grupos que estão sob sua tutela" (CARVALHO, 2005, p. 267).

Ao longo da história, encontramos momentos em que a família assumia quase exclusivamente essa função, enquanto na contemporaneidade compartilha com o Estado, através das políticas públicas, a tarefa de proteger seus membros, principalmente em situações de risco e vulnerabilidade.

Entretanto, sabemos que apesar da centralidade da família nas políticas públicas, nem sempre as famílias conseguem receber a proteção necessária para garantir a sobrevivência e o bem estar de seus membros ou por vezes a recebem apenas depois de instalado o prejuízo os seus membros. Inúmeras situações vividas cotidianamente, como desemprego, pobreza, desigualdade, exclusão social, contexto de violência, contribuem para que as famílias e seus membros sejam expostos a situações de vulnerabilidade e risco, inclusive aquelas em que crianças e adolescentes são afastados de suas famílias naturais e encaminhados para instituições de acolhimento.

A preocupação com a qualidade dos serviços de acolhimento a crianças e adolescentes fomentou a elaboração do Guia de Orientações Técnicas para os Serviços de Acolhimento para Crianças e Adolescentes, desenvolvido em parceria com o Ministério do Desenvolvimento Social e Combate à Fome, a Secretaria de Direitos Humanos, o CONANDA e o CNAS, que identificou/definiu as modalidades de atendimento a crianças e adolescentes que versam sobre a proteção dessa clientela e sobre os parâmetros de funcionamento de tais serviços, visando regulamentá-los, tal como foi previsto no Plano Nacional de Promoção, Proteção e Defesa do Direito de Crianças e Adolescentes à Convivência Familiar e Comunitária.

Nossa experiência profissional no Poder Judiciário nos colocou em contato com ações judiciais iniciadas em razão do acolhimento institucional de crianças e adolescentes, sendo tal medida aplicada sob a justificativa da 
necessidade de proteção à sua integridade física, psíquica e/ou social. Diante dessa realidade, se apresenta a nós um grande desafio: viabilizar o direito à convivência familiar seja em família de origem ou através da colocação em família substituta.

Para enfrentar tal desafio, é imprescindível que a rede de apoio social e comunitária disponível para as famílias dessas crianças e adolescentes seja acionada, tendo em vista que a proteção integral e a busca de garantia de direitos podem perpassar o Poder Judiciário, mas se efetivam nas políticas públicas de atendimento a esta clientela e nos recursos da comunidade. Dessa forma, destacase a relevância de que as Varas da Infância e da Juventude, enquanto instrumentos dessa realidade, se entrelacem aos demais serviços e atores sociais envolvidos, a fim de se aproximar e de integrar tais recursos e minimizar dificuldades.

A superação desse desafio foi o que nos motivou a compartilhar nossa experiência, através da qual buscamos reiteradamente construir uma rede social na perspectiva de garantir direitos a crianças e adolescentes em situação de acolhimento institucional. Além de apresentarmos tal experiência, trazemos também reflexões e questionamentos sobre o acolhimento institucional como medida de (des)proteção a crianças e adolescentes que tiveram seus diretos ameaçados e/ou violados.

\section{AS INSTITUIÇÕES DE ACOLHIMENTO E A CONSTRUÇÃO DA REDE SOCIAL EM BATATAIS-SP}

O Município de Batatais está localizado na região nordeste do interior Estado de São Paulo, possui uma população de pouco mais 56.481 habitantes, conforme censo realizado em 2010, e um Índice de Desenvolvimento Humano Municipal de 0.825, medido em 2000.

Batatais é a Comarca Sede da 39a aircunscrição, local onde desenvolvemos atividade profissional. No Município, não existem políticas de atendimento nas modalidades "casa-lar", "famílias acolhedoras" e "república", havendo duas instituições destinadas ao acolhimento de crianças e adolescentes, a saber:

- Casa Abrigo Moysés de Oliveira - acolhe crianças e adolescentes do sexo feminino e crianças do sexo masculino, com capacidade para acolher 25 pessoas. 
- Casa Abrigo Hernani Albuquerque Parente - atende adolescentes do sexo masculino, com disponibilidade para 12 vagas.

O encaminhamento de crianças e adolescentes às referidas instituições se dá após intervenção do Conselho Tutelar, em caráter excepcional, ou, quando há solicitação/indicação do representante do Ministério Público, por determinação do Juiz da Infância e Juventude, o qual também é informado da aplicação das medidas de acolhimento realizada pelo Conselho devendo ratificar tal conduta e/ou determinar outras providências, o que desencadeia a instauração de ações de acolhimento institucional quando tal medida é mantida.

O trâmite usual nas mencionadas ações, que tramitam na Seção da Infância e Juventude, é o encaminhamento do caso ao Setor Técnico do Judiciário com a determinação de realização do estudo técnico, o qual subsidia a decisão judicial em relação ao caso. Consideramos que as situações de acolhimento institucional exigem a intervenção dos profissionais tanto do Serviço Social quanto da Psicologia, visto que envolvem questões de ambas as áreas do saber.

$\mathrm{Na}$ realização do estudo psicossocial, os profissionais utilizam diversos instrumentais técnicos, tais como: leitura dos Autos, observação, entrevistas, sessões lúdicas, visitas domiciliares e na instituição onde a criança/adolescente encontra-se acolhido e contatos com recursos da comunidade, buscando conhecimentos das condições objetivas e subjetivas da situação. Sistematicamente, o Setor Técnica realiza reunião interprofissional com técnicos das instituições de acolhimento, do Centro de Referência de Assistência Social (CRAS) e do Centro de Referência Especializado de Assistência Social (CREAS), bem como com os Conselheiros Tutelares, de forma a se avaliar aprofundadamente $o$ caso.

Assim, procura-se conhecer a organização/dinâmica familiar da criança/adolescente acolhido, avaliando seus recursos protetivos, as adversidades vivenciadas, os aspectos que deram origem ao acolhimento institucional, bem como se identifica a rede social existente e utilizada pela família e aquela que poderá ser acionada no intuito de fortalecer os recursos da própria família.

Os estudos realizados caso a caso pelos técnicos do Judiciário indicavam que em muitas situações os acolhimentos institucionais eram efetuados já na primeira situação de denúncia de ameaça ou violação de direitos, sem que houvesse 
qualquer outra ação, menos drástica e que trouxesse menor sofrimento para a criança/adolescente.

Assim, a realização do estudo psicossocial apontava para uma primeira vertente desta problemática: tendo em vista que a medida de proteção denominada "acolhimento institucional" é excepcional e de urgência, sendo consignado que sua aplicação será o último recurso de proteção ou aquele em situação extrema. Consideramos que o acolhimento institucional de algumas crianças e adolescentes poderia ter sido evitado diante de políticas públicas consistentes e articuladas, que compreendessem e intervissem adequadamente na realidade das famílias que vivenciam situações adversas para as quais não encontram recursos internos de enfrentamento.

Cabe ressaltar que o sistema de garantias de direitos de Batatais-SP, cidade foco deste estudo, conta com serviços de promoção para assegurar os direitos de crianças e adolescentes, bem como com serviços de proteção especial, desenvolvidos diante da ameaça e/ou comprovação de violação de direitos. Destacamos, assim, a existência no referido município de: creches e escolas (ensino infantil, fundamental, técnico e médio), serviços médicos de atenção primária, secundária e terciária, programas pedagógicos desenvolvidos pela Prefeitura e por ONGs, programas de esporte e lazer, programa de geração de renda para adolescentes e adultos, CRASs - Centros de Referência da Assistência Social, Conselho Tutelar, serviço ambulatorial de atendimento psicológico, CREAS - Centro de Referência Especializado em Assistência Social, instituições de acolhimento, serviços para execução de medidas sócio-educativas (prestação de serviço à comunidade, liberdade assistida e unidade de semi-liberdade), Delegacia de Defesa da Mulher, Vara da Infância e da Juventude e Promotoria da Infância e Juventude. Por outro lado, uma ausência identificada no município se refere aos serviços públicos especializados no atendimento a adolescentes com dependência química e na saúde mental de crianças e adolescentes, com destaque para a inexistência no Município de psiquiatra infantil.

Tal realidade evidencia que o município de Batatais-SP vem se estruturando ao longo das últimas duas décadas, no sentido de implementar ações e parcerias a fim de proporcionar aos munícipes políticas de atendimento a crianças e adolescentes, bem como suas famílias, de acordo com o estabelecido no ECA. 
Um dos pressupostos para a busca de garantias dos direitos de crianças e adolescentes é a implementação de políticas públicas. O artigo 87 do ECA ressalta que as linhas de ação da política de atendimento a crianças e adolescentes incluem: (a) as políticas sociais básicas, (b) as políticas e programas de assistência social, (c) os serviços especiais de prevenção e atendimento médico e psicossocial às vítimas de negligência, maus tratos, exploração, abuso, crueldade e opressão, (d) os serviços de localização de pais, responsáveis, crianças e adolescentes desaparecidos e (e) os serviços de proteção jurídico-social. Tal implementação deve ser desenvolvida de forma integrada, de modo a se preservar as particularidades e competências de cada serviço.

Ressaltamos que a implementação, no cotidiano de trabalho dos diversos atores sociais das diretrizes da Nova Lei de Adoção propiciou um novo ordenamento e fluxo de atendimento à infância e juventude em Batatais, na medida em que as intervenções de busca e garantia de direitos das crianças e adolescentes estão ocorrendo de forma mais articulada entre os órgãos e serviços. Com isso, o Judiciário local passou a atuar exclusivamente nos casos em que há de fato a necessidade de intervenção desta autoridade.

Ainda assim, o Poder Judiciário, em especial a Vara da Infância e da Juventude, é constantemente acionado pelos serviços e órgãos de atenção à criança e ao adolescente, principalmente pelo Conselho Tutelar e Ministério Público, como forma de garantir a proteção desta parcela da população. Nessa tarefa, o Assistente Social e o Psicólogo Judiciários têm um papel de significativa importância, pois é através do trabalho desses profissionais que a autoridade judiciária irá conhecer a realidade de crianças e adolescentes cujos direitos foram ameaçados e/ou violados e, a partir daí, determinar as medidas necessárias para que a proteção a essa clientela seja restituída.

Nos estudos técnicos elaborados pelos profissionais da Vara da Infância e Juventude, observa-se que as pessoas envolvidas nas diferentes ações que tramitam nesta Vara, e em especial as situações de acolhimento institucional, estão inseridas em um ambiente familiar e em uma comunidade atendida pelos diversos serviços governamentais e não governamentais apontados anteriormente. Assim, identificamos no Município de Batatais a presença de recursos externos às famílias, contudo, o fato de que, no passado, se buscava sistematicamente a intervenção do 
Poder Judiciário pode indicar que tais serviços falhavam ou não eram devidamente acionados para proteger as crianças e os adolescentes e suas respectivas famílias.

Diante dessa realidade, é imprescindível que juntamente com a implementação das diretrizes da Nova Lei de Adoção se defina a competência de cada órgão/instituição que compõe a rede de apoio social e comunitária disponíveis, tendo em vista que as intervenções sistemáticas nas áreas de assistência social, saúde, educação, etc, são executadas pela referida rede.

Quando se soma a tal contexto a questão do acolhimento institucional, destacamos que o atendimento em rede deve se instalar o quanto antes a fim de garantir proteção à criança e ao adolescente, oferecendo-lhe condições para desenvolver suas potencialidades e auxílio diante das dificuldades e limitações mediante atendimento individualizado. Esse atendimento deve estar previsto no PIA - Plano Individualizado de Atendimento e poderá contar com recursos da saúde (incluindo a saúde mental), da educação formal, de programas sociais governamentais ou não-governamentais na tentativa de restabelecer ou favorecer seu desenvolvimento.

Além disso, Winnicott aponta para a necessidade de oferecimento à criança e ao adolescente de relações interpessoais que resgatem sua confiança básica, afirmando que "é necessário que se edifique, no interior de cada criança, a crença em algo que não seja apenas bom, mas seja confiável e durável, ou capaz de recuperar-se depois de se ter machucado ou mesmo perecido (2001, p. 44), sendo tais considerações importantes de serem levadas em conta também na situação de acolhimento institucional.

Com a aplicação de tal medida protetiva, a reinserção familiar passa a ser alvo da atenção de todos aqueles envolvidos com a situação da criança/adolescente acolhido institucionalmente, quais sejam: profissionais do Poder Judiciário, das instituições de acolhimento, do Conselho Tutelar, bem como de toda a rede de atenção à família, que devem unir esforços para que esta seja potencializada a resgatar sua capacidade protetiva, de modo a acolher novamente a criança/adolescente.

Assim, na tentativa de acionar e fortalecer a rede social de proteção a essas crianças, adolescentes e suas famílias, adotou-se a sistemática das reuniões mensais referidas, nas quais são definidas estratégias para cada caso, de forma que 
as famílias possam receber o apoio/suporte necessário para resgatar sua capacidade protetiva, bem como são traçadas as expectativas de ação das próprias famílias, que são explicitadas aos familiares para reflexão e para que se tenha um compromisso de todos os envolvidos. Assim, identificam-se, coletivamente, as necessidades de cada família, criança e adolescente, e se acionam os serviços responsáveis por tais demandas.

Além disso, diante da possibilidade de retorno da criança e adolescente à sua família de origem, é definida a responsabilidade de cada serviço quanto ao acompanhamento do referido grupo familiar após o desligamento da instituição de acolhimento. Tal medida visa evitar atendimentos sobrepostos, desarticulações e incongruências, bem como possíveis falhas na política de proteção social.

\section{NOSSAS REFLEXÕES E CONSIDERAÇÕES FINAIS}

As mudanças na legislação e no discurso dos atores sociais referentes à infância e à juventude vêm sendo absorvidas gradativamente, contudo ainda não de forma integral pelas práticas de atendimento a estes cidadãos, de modo que as políticas de atendimento e a articulação entre elas carecem de uma organização e sistematização que seja reflexo dos ideais para essa clientela.

A prática profissional no Poder Judiciário, de modo especial mediante a realização de estudos psicossociais e do acompanhamento aos casos de crianças/adolescentes que estão acolhidos institucionamente, nos leva a refletir sobre algumas questões presentes no contexto do acolhimento institucional.

Após o acolhimento institucional, o foco central dos profissionais envolvidos com a questão, sem dúvida alguma, é a reinserção familiar. Entretanto, nota-se que a própria situação de vulnerabilidade a que a família estava exposta anteriormente à aplicação da medida protetiva, associada à ausência de políticas públicas capazes de atender de forma articulada as demandas destas famílias, representa tanto uma condição que favorece o acolhimento instituicional quanto uma dificuldade para viabilizar a reinserção da criança e do adolescente em sua família de origem. Soma-se a isso a existência de concepções preconceituosas que consideram o acolhimento institucional a "primeira e única" medida de proteção a ser 
utilizada em situação de crianças e adolescentes que tiveram seus direitos ameaçados ou violados, sem levar em conta que o próprio acolhimento pode também representar a violação ao direito à convivência familiar.

As limitações relativas às dificuldades das políticas públicas de proteção à criança, ao adolescente e à família de trabalho articulado, de ações de promoção da saúde mental e de diagnóstico precoce das situações de vulnerabilidade e risco parecem contribuir de forma relevante para o prolongamento da medida, dificultando a garantia de sua provisoriedade e excepcionalidade.

Nesse sentido, consideramos necessário o incremento de ações públicas e privadas, envolvendo o Estado e a sociedade, de maneira coerente, complementar e articulada, na busca pelo fortalecimento das famílias e da conviência familiar. Tal convivência é pensada prioritariamente no seio da família biológica, sendo a adoção o último recurso de proteção a ser utilizado visando a garantia do direito à convivência familiar. Ainda existem diversos questionamentos sobre o "quanto" se deve investir nas famílias biológicas para que acolham seus filhos e "quando" é o momento de direcionar as ações no sentido de inserção em família adotiva, evidenciando um contexto que precisa de delimitações mais claras ou que contemplem as particularidades de cada situação.

Destacamos, pois, a necessidade de mudanças relevantes no processo de proteção a crianças e adolescentes acolhidos institucionalmente. Tais mudanças precisam passar necessariamente pela reflexão sistemática, organizada e despida de preconceitos quanto à realidade dessa parcela da população, o que será possível desde que haja engajamento e o compromisso dos vários atores sociais que se entrelaçam nesta rede composta pelo poder público, pela sociedade civil e pela iniciativa privada. 


\section{REFERÊNCIAS}

ACOSTA, Ana Rojas, VITALER, Maria Amália Faller (org). Família: redes, laços e políticas públicas. São Paulo: Cortez: Instituto de Estudos Especiais-PUC/SP, 2005.

BRASIL. Estatuto da Criança e do Adolescente. Lei Federal $n \cong 8069 / 90$. Ministério da Justiça, Brasília, DF, 1990.

BRASIL. Plano Nacional de Promoção, Proteção e Defesa do Direito de Crianças e Adolescentes à Convivência Familiar e Comunitária. Brasília: Ministério do Desenvolvimento Social e Combate à Fome- Secretaria Especial dos Direitos Humanos, 2006

BRASIL. Orientações técnicas para os serviços de acolhimento para crianças e adolescentes. Conanda/ CNAS, Brasília, DF, 2009.

BRASIL. Lei Federal $n^{\circ}$ 12.010/ 09. Brasília, DF, 2009.

CARVALHO, Denise B. B. de. Políticas Sociais setoriais e por segmento - Criança e Adolescente. In: Programa de capacitação em Serviço Social e Política Social módulo 3. Brasília: UNB-CEAD, 2000.

ELKIND, D. The child yesterday, today and tomorrow. Young Children, 42(4), 1987, p. 6-11.

FUNDAÇÃO ABRINQ. O Abrigo como possibilidade. São Paulo: Instituto Camargo e Corrêa, 2006.

OLIVEIRA, Rita C.S. (coord.) Quero voltar para casa: o trabalho em rede e a garantia do direito à convivência familiar e comunitário para crianças e adolescentes que vivem em abrigos. São Paulo: AASPTJ-SP, 2007.

ORIENTAÇÕES TÉCNICAS PARA OS SERVIÇOS DE ACOLHIMENTO DE CRIANÇAS E ADOLESCENTES. Cnas/Conanda, 2008. Arquivo disponível em http://www.mds.gov.br/cnas/noticias. Acesso em: 24 maio 2010.

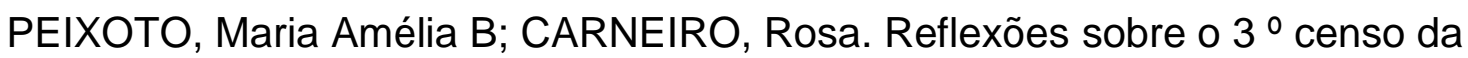
população infantojuvenil abrigada no Estado do Rio de Janeiro. Disponível em: http://www.mp.rj.gov.br/portal/page/portal/MCA/Censo/Terceiro_Censo/9_Reflexoes. pdf. Acesso em: 03 maio 2010.

RIZZINI, Irene. A criança e a lei no Brasil: revisitando a história (1822-2000). Brasília: UNICEF; Rio de Janeiro: USU Universitária, 2000.

SILVA, Alexandre Pereira da; SILVA, Eliana Beserra da; AZEVEDO, Simone Mendes de. O direito à convivência familiar: reflexões a partir da inserção do assistente social na vara da infância, da juventude e do idoso. In: CD-R Anais da 19a Conferência Mundial de Serviço Social. Salvador, 2008. 
SLUZKI, Carlos E. A rede social na prática sistêmica: alternativas terapêuticas. São Paulo: Casa do Psicólogo, 1997.

VICENTE, C.M. O direito à convivência familiar e comunitária: uma política de manutenção do vínculo. In: KALOUSTIAN, Sílvio M. (org). Família brasileira: a base de tudo. São Paulo: Cortez, 1994.

WALSH, F. Fortalecendo a resiliência familiar. São Paulo: Roca, 2005

WINNICOTT, D.W. A família e o desenvolvimento individual. São Paulo: Martins Fontes, 2001. 